\title{
Systematic Review of Inspiratory Muscle Training After Cerebrovascular Accident
}

\author{
Rocío Martín-Valero PhD, Maria De La Casa Almeida PhD, Maria Jesus Casuso-Holgado PhD, \\ and Alfonso Heredia-Madrazo MSc
}

\author{
Introduction \\ Methods \\ Database Search \\ Inclusion and Exclusion Criteria \\ Evaluation of Methodological Quality \\ Results \\ Discussion \\ Evidence of Respiratory Muscle Training With a Threshold Valve in \\ Subjects After Stroke \\ Practical Implications of the Incentive Spirometer for Ventilatory \\ Re-Education \\ Threshold Devices to Train Respiratory Muscles
}

\begin{abstract}
This systematic review examines levels of evidence and recommendation grades of various therapeutic interventions of inspiratory muscle training in people who have had a stroke. Benefits from different levels of force and resistance in respiratory muscles are shown in this population. This review was conducted following the PRISMA (Preferred Reporting Items for Systematic Reviews and Meta-Analyses) directives and was completed in November 2014. The search limits were studies published in English between 2004 and 2014. Relevant studies were searched for in MEDLINE, PEDro, OAIster, Scopus, PsycINFO, Web of Knowledge, CINAHL, SPORTDiscus, DOAJ, Cochrane, Embase, Academic Search Complete, Fuente Académica, and MedicLatina. Initially, 20 articles were identified. After analyzing all primary documents, 14 studies were excluded. Only 6 studies were relevant to this review. Three different types of interventions were found (maximum inspiratory training, controlled training, and nonintervention) in 3 different groups. One specific study compared 3 inspiratory muscle training groups with a group of breathing exercises (diaphragmatic exercises with pursed lips) and a control group. Future long-term studies with larger sample sizes are needed. It is necessary to apply respiratory muscle training as a service of the national health system and to consider its inclusion in the conventional neurological program. Key words: stroke; inspiratory muscle training; threshold valve; pulmonary function; physical therapy; systematic review. [Respir Care 2015;60(11):1652-•. (c) 2015 Daedalus Enterprises]
\end{abstract}

Introduction

People who have had a cerebrovascular accident have a greater risk of associated pneumonias, which involve in-

Drs Martín-Valero, De La Casa Almeida, and Casuso-Holgado are affiliated with the Francisco Maldonado University School of Osuna, Osuna, Spain. Mr Heredia-Madrazo is a freelance computer engineer in Málaga.

Supplementary material related to this paper is available at http:// www.rcjournal.com. creased morbidity and mortality and a high consumption of drugs. ${ }^{1,2}$ Cerebrovascular diseases or stroke is the third most frequent cause of death in developed countries, only after heart disease and cancer. ${ }^{3}$ It has been observed that

The authors have disclosed no conflicts of interest.

Correspondence: R Martín-Valero PhD, Department of Psychiatry and Physiotherapy, Francisco Maldonado University School of Oduna, Campo de Cipreses, 1, 41640 Osuna (Sevile), Spain. E-mail: rovalemas@gmail.com.

DOI: $10.4187 /$ respcare.03981 
subjects who have had a cerebrovascular accident have weak respiratory muscles. ${ }^{4}$ Patients after stroke show a restrictive pattern, with significant reduction in the maximum voluntary ventilation and maximum respiratory pressures coupled with an altered dynamic costal and diaphragmatic movement. Currently, nonpharmacologic treatment and therapeutic exercise training are necessary to prevent stroke-associated pneumonia to improve the effectiveness of a cough. ${ }^{5}$

Three-quarters of strokes affect patients over $65 \mathrm{y}$ of age because of the aging population in the area. ${ }^{3}$ Strokes are also the most significant permanent disability in Europe; therefore, strokes create a cumbersome economic load for families and the community.

There is evidence of the benefits of peripheral muscle training in subjects after stroke. ${ }^{6}$ However, there is little literature on respiratory muscle training in this population. Only a systematic review on respiratory muscle training in neurological subjects exists. ${ }^{7}$ No large-scale studies have been conducted using threshold pressure devices during breathing exercises in subjects after stroke. Several studies showed consistent results according to the use of inspiratory exercises with threshold devices to improve the strength of respiratory muscles; however, these studies had small sample sizes. ${ }^{8,9}$

A 4-week study combined inspiratory exercises and expiration with pursed lips, which significantly improved Tiffeneau index $\left(\mathrm{FEV}_{1} / \mathrm{VC}\right)$, total volume, and inspiratory capacity. ${ }^{10}$ Undoubtedly, subjects seated with the spine at $90^{\circ}$ had better mobility in the thoracic cage, which significantly favored better maximum inspiration with respect to the supine position. ${ }^{11}$ Furthermore, it was observed that the therapeutic inspiratory muscle training intervention had functional effects on the recovery of subjects after stroke. ${ }^{4}$ There are studies that support inspiratory muscle training interventions ${ }^{5,8-10,12}$; however, more studies are needed to determine whether patients who have had a cerebrovascular accident can improve respiratory muscle strength and endurance to improve their quality of life.

The main aim of this review was to detect the level of evidence and grade of recommendation according to the inspiratory muscle training interventions of subjects after stroke. Therefore, it is necessary to develop the most appropriate protocol to improve respiratory muscle weakness and pulmonary function according to the aims of the respiratory therapist and physiotherapists.

\section{Methods}

\section{Database Search}

This review was performed following the guidelines of PRISMA (Preferred Reporting Items for Systematic
Reviews and Meta-Analyses; www.prisma-statement. org/statement.htm, Accessed July 28, 2015), ${ }^{13}$ The initial search was carried out in January and February 2014 and was completed with a new search to update the review in November 2014. The literature searches were performed to identify all possible studies that could help answer the research question. MEDLINE, PEDro, OAIster, Scopus, PsycINFO, Web of Knowledge, CINAHL, SPORTDiscus, DOAJ, Cochrane, Embase, Academic Search Complete, Fuente Académica, and MedicLatina were searched. In addition, the search was performed in a relevant bibliographic database. Twenty articles were identified in this systematic review. All reference lists of the revised articles were reviewed. Abstracts published in conferences and congresses were also considered.

Two reviewers performed several searches in the databases. The following combinations of key words were used: stroke, cerebrovascular accident, threshold valve, respiratory muscle training, respiratory exercises, and threshold training of inspiratory muscles. The limits of searches were studies published in English between 2004 and 2014.

\section{Inclusion and Exclusion Criteria}

Inclusion criteria were considered using the PICO (population, intervention, control/comparison, and outcome variables) model. First, subjects who were included had experienced a moderate or severe stroke according to the National Institutes of Health Stroke Scale with a score of 5-25 at the time of admission. ${ }^{14}$ Second, the intervention included inspiratory exercises of different intensities and duration through resistance, which was controlled by a threshold valve adapted to the needs and changes of people after stroke as soon as subjects progressed through the study. Third, different types of studies were included: 2 randomized trials, 3 cross-sectional studies, and a pilot study. Furthermore, 3 different types of interventions were included (maximum inspiratory training, controlled intervention, and nonintervention $)^{8}$ in 3 different groups. One group (control group) carried out a neurological rehabilitation program (NRP) simultaneously with respiratory muscle training at a constant load of $10 \%$, the second group carried out a NRP program and expiratory muscle training with resistance at $50 \%$, and the last group carried out a NRP and inspiratory muscle training with resistance at $50 \% .5$ There also was a study with 3 groups that compared inspiratory muscle training with a group of breathing exercises combined with diaphragmatic exercises with pursed lips and a control group. ${ }^{9}$

Finally, the outcome measures included functional maximum inspiratory pressure $\left(\mathrm{P}_{\mathrm{I}_{\max }}\right),{ }^{8}$ maximum expiratory pressure $\left(\mathrm{P}_{\mathrm{E}_{\max }}\right)$, respiratory muscle strength, $\mathrm{FVC}, 5$ inspiratory capacity, and forced expiratory peak., ${ }^{5,9}$ Other functional outcome measures, such as Nottingham Health 
Table 1. Evaluation of Methodological Quality of the 6 Selected Studies

\begin{tabular}{|c|c|c|c|c|c|c|}
\hline Section/Theme & Britto et $\mathrm{al}^{8}$ & Sutbeyaz et $\mathrm{al}^{9}$ & Kulnik et $\mathrm{a}^{5}$ & Polese et al ${ }^{19}$ & Silva et $\mathrm{a}^{20}$ & Pinheiro et $\mathrm{al}^{21}$ \\
\hline Eligibility criteria & Yes & Yes & Yes & Yes & Yes & Yes \\
\hline Randomization & Yes & Yes & Yes & No & No & No \\
\hline Allocation concealed & Yes & Yes & Yes & No & No & No \\
\hline Baseline comparability & Yes & Yes & No & No & No & No \\
\hline Subject blinding & Yes & No & No & No & No & No \\
\hline Therapist blinding & Yes & No & No & No & No & No \\
\hline Evaluator blinding & No & No & No & No & No & No \\
\hline Appropriate continuation & No & No & No & No & No & No \\
\hline Intention to treat & No & Yes & No & No & No & No \\
\hline Comparison between groups & Yes & Yes & Yes & Yes & Yes & Yes \\
\hline Specific measurements and variability & Yes & Yes & No & Yes & Yes & Yes \\
\hline Total & 8 & 7 & 4 & 3 & 3 & 3 \\
\hline
\end{tabular}

Profile and a self-report questionnaire measuring the level of maximum physical activity, ${ }^{8}$ were also included.

Studies were excluded if subjects had cognitive difficulties or an intracranial pressure increase.$^{5}$ In addition, studies were also excluded if the respiratory intervention focused on drainage techniques or aerobic training of peripheral muscles without respiratory muscle training with thresholds valves or only on ventilatory exercises with an incentive spirometer. Six studies were examined after subsequent selection based on the title and abstract. The excluded studies are listed in Appendix 1 (see the supplementary materials at http://www.rcjournal.com).

\section{Evaluation of Methodological Quality}

Twenty relevant articles were found in the main databases. Six original studies were examined after subsequent selection based on the title and abstract. After analyzing all primary documents, 6 studies were relevant to this review: 2 randomized controlled clinical trials, 3 cross-sectional studies, and a pilot study. Fourteen articles were excluded because they did not reference inspiratory training with threshold valves in subjects with stroke.

The methodological quality of the 6 studies was evaluated using the PEDro scale. ${ }^{15-17}$ Two independent reviewers (RM-V and MJC-H) completed the checklist based on the PEDro scale. This scale $(0-10)$ is based on a list developed by Verhagen et al. ${ }^{18}$ The internal validity of the randomized controlled trials was evaluated. A study with a PEDro score of $\leq 6$ is considered to have a level 1 of evidence $(6-8=$ good, $9-10=$ excellent $)$ and a study with a score of $\geq 5$ is considered to have a level 2 of evidence $(4-5=$ acceptable, $<4=$ poor $) .{ }^{17}$

Studies included in this review had PEDro scores of 3-8, as shown in Table 1. Studies were considered of high enough methodological quality if they had a score of at least 5. This was based on the fact that studies with a score closer to 4 did not employ a triple-blind methodology (subject, evaluator, and treatment provider). Applying this evaluation, 2 randomized controlled trials were found to have scores of 7 and 8 , respectively; the pilot study had a score of 4; and the 3 cross-sectional studies each scored a 3 . The grades of recommendation are listed in Table 2 .

\section{Results}

The main findings of this review are presented in Table 1 , an evaluation of the methodological quality of the studies selected according to the PEDro scale. Table 2 shows the articles reviewed regarding the effectiveness of inspiratory training in subjects after stroke. Three articles were found that included information about spirometers. ${ }^{10,12,22}$ In these articles, respiratory muscle training, performed using threshold pressure load in inspiratory muscles, was included. ${ }^{23} \mathrm{~A}$ meta-analysis of the data from the randomized clinical trials was included in this review and is presented in Figure 1.

\section{Discussion}

This systematic review summarizes the levels of evidence and recommendation grades of different therapeutic respiratory muscle training interventions in subjects after stroke. It has been observed that respiratory muscle training can improve respiratory muscle strength $\left(\mathrm{P}_{\mathrm{I}_{\max }}\right)$ and inspiratory muscle endurance (IME) in this population. These findings support the benefits found in subjects with multiple sclerosis ${ }^{24}$ and COPD. ${ }^{25}$ In addition, 3 cross-sectional studies were found ${ }^{19-21}$ recommending the inclusion of respiratory muscle training in the PR program for subjects after stroke. 


\section{Inspiratory Muscle Training in SubJects After Stroke}

Table 2. Revised Articles About the Effectiveness of Inspiratory Training in Subjects After Stroke

\begin{tabular}{|c|c|c|c|c|}
\hline Reference & $\begin{array}{l}\text { PEDro }(n) \text {, Type of } \\
\text { Evidence, } \\
\text { Recommendation } \\
\text { Grade }\end{array}$ & Main Intervention & $\begin{array}{l}\text { Clinical Outcome } \\
\text { Measures }\end{array}$ & Self-Reported Outcome Measures \\
\hline \multirow[t]{3}{*}{ Britto et $\mathrm{al}^{8}$} & \multirow[t]{3}{*}{$\begin{array}{l}\text { PEDro } 8 / 10(N=21) \\
\text { RCT, A }\end{array}$} & $\begin{array}{l}\text { 8-wk home treatment, threshold resistance } \\
\text { device supplemented with cycle } \\
\text { ergonomic training } 5 \text { times/wk, } 6 \text { sets } \\
\text { ( } 5 \text { min/set }), 1 \text { min between sets, } 30 \mathrm{~min} / \\
\text { d }\end{array}$ & $\mathrm{P}_{\mathrm{I}_{\max }}(P=.004)$ & $\begin{array}{l}\text { Brazilian quality-of-life questionnaire } \\
\text { and Nottingham Health Profile } \\
(P=.10)\end{array}$ \\
\hline & & Control group: training without resistance & $\begin{array}{l}\text { Inspiratory } \\
\text { muscle } \\
\text { endurance } \\
(P=.02)\end{array}$ & $\begin{array}{l}\text { Scores for maximum level of } \\
\text { physical activity of } 76 \text { and } 79 \text { for } \\
\text { experimental and control groups } \\
\text { (not significant) }\end{array}$ \\
\hline & & $\begin{array}{l}\text { Group 1, inspiratory muscle training at } \\
30 \% \mathrm{P}_{\mathrm{I}_{\max }}\end{array}$ & $\begin{array}{l}\operatorname{FEV}_{1}(P=.050) \\
\operatorname{FVC}(P=.78)\end{array}$ & \\
\hline \multirow[t]{4}{*}{ Sutbeyaz et al ${ }^{9}$} & \multirow[t]{4}{*}{$\begin{array}{l}\text { PEDro } 7 / 10(N=45) \\
\quad \text { RCT, A }\end{array}$} & $\begin{array}{l}\text { 6-wk neurological rehabilitation program } \\
\text { supplemented with threshold resistance, } \\
6 \text { times/wk, } 6 \text { sets }(5 \mathrm{~min} / \mathrm{set}), 2 \text { times/ } \\
\text { d }(15-\mathrm{min} / \mathrm{session}), 30 \mathrm{~min} / \mathrm{d}, 1 \mathrm{~min} \\
\text { break between session }\end{array}$ & $\mathrm{P}_{\mathrm{I}_{\max }}(P<.001)$ & $\begin{array}{l}\text { Brunnstrom stages: upper extremity } \\
\qquad \begin{array}{l}(P=.69) \text { and lower extremity } \\
(P=.22)\end{array}\end{array}$ \\
\hline & & $\begin{array}{l}\text { Control group: neurological rehabilitation } \\
\text { program }+ \text { diaphragmatic exercises } \\
\text { with pursed lips }\end{array}$ & $\mathrm{P}_{\mathrm{E}_{\max }}(P=.001)$ & $\begin{array}{l}\text { Functionality in ambulation capacity } \\
\qquad(P=.48)\end{array}$ \\
\hline & & $\begin{array}{l}\text { Intervention group 1: neurological } \\
\text { rehabilitation program }+ \text { inspiratory } \\
\text { muscle training at } 40 \% \mathrm{P}_{\mathrm{I}_{\max }} \text { and } \\
\text { gradual increase from } 5-10 \% \text { session to } \\
60 \%\end{array}$ & $\mathrm{PEF}(P=.06)$ & $\begin{array}{l}\text { Barthel Activities of Daily Living } \\
\quad \text { Index }(P=.83)\end{array}$ \\
\hline & & $\begin{array}{l}\text { Intervention group } 2 \text { : neurological } \\
\text { rehabilitation program }+ \text { diaphragmatic } \\
\text { exercises with pursed lips }\end{array}$ & $\begin{array}{l}\mathrm{FEV}_{1}(P=.01) \\
\mathrm{FVC}(P=.01) \\
\dot{\mathrm{V}}_{\mathrm{O}_{2}} \text { peak } \\
\quad \text { improved in } \\
\quad \text { intervention } \\
\quad \text { group } 1 \\
\quad(P=.01)\end{array}$ & $\begin{array}{l}\text { Dyspnea } \\
\text { 36-Item Medical Outcomes Study } \\
\text { Short Form questionnaire }\end{array}$ \\
\hline \multirow[t]{4}{*}{ Kulnik et al ${ }^{5}$} & \multirow[t]{4}{*}{$\begin{array}{l}\text { PEDro: } 4 / 10(N=48) \\
\text { pilot study, } \mathrm{C}\end{array}$} & $\begin{array}{l}\text { 4-wk neurological rehabilitation program } \\
\text { supplemented with threshold resistance, } \\
3 \text { times/wk, } 5 \text { sets (10 breaths/set), } \\
\text { once/d }\end{array}$ & $\mathrm{P}_{\mathrm{I}_{\max }}$ & \multirow[t]{4}{*}{$\begin{array}{l}\text { Nottingham daily living activities } \\
\text { extended questionnaire }\end{array}$} \\
\hline & & $\begin{array}{l}\text { Control group: neurological rehabilitation } \\
\text { program }+ \text { training } 10 \% \mathrm{P}_{\mathrm{I}_{\max }}\end{array}$ & $\mathrm{P}_{\mathrm{E}_{\max }}$ & \\
\hline & & $\begin{array}{l}\text { Intervention group 1: neurological } \\
\text { rehabilitation program }+ \text { inspiratory } \\
\text { muscle training at } 50 \% \mathrm{P}_{\mathrm{I}_{\max }}\end{array}$ & $\begin{array}{l}\text { Peak expiratory } \\
\text { cough flow }\end{array}$ & \\
\hline & & $\begin{array}{l}\text { Intervention group 2: neurological } \\
\text { rehabilitation program + EMT at 50\% } \\
\mathrm{P}_{\mathrm{E}_{\max }}\end{array}$ & $\begin{array}{l}\mathrm{FEV}_{1} \\
\mathrm{FVC}\end{array}$ & \\
\hline Polese et $\mathrm{al}^{19}$ & $\begin{array}{l}\text { PEDro: } 3 / 10(N=98) \\
\text { cross-sectional study, } \\
\text { C }\end{array}$ & $\begin{array}{l}\text { Comparison of strength and functional } \\
\text { capacity in chronic stroke subjects } \\
\text { according to their physical activity } \\
\text { levels: impaired, moderately active, and } \\
\text { active }\end{array}$ & $\begin{array}{l}\mathrm{P}_{\mathrm{I}_{\max }}(P=.13) \\
\mathrm{P}_{\mathrm{E}_{\max }}(P=.40) \\
6 \mathrm{MWT} \\
\quad(P<.001)\end{array}$ & $\begin{array}{l}\text { Human Activity Profile: impaired, } \\
\quad<53 \text {; moderately active, 53-74; or } \\
\text { active, }>74\end{array}$ \\
\hline Silva et $\mathrm{al}^{20}$ & $\begin{array}{l}\text { PEDro: } 3 / 10(N=29) \text {, } \\
\text { cross-sectional study, } \\
\text { C }\end{array}$ & $\begin{array}{l}\text { Comparison of respiratory muscle } \\
\text { strength in elderly stroke subjects in } \\
\text { acute and chronic phases }\end{array}$ & $\begin{array}{l}\mathrm{P}_{\mathrm{I}_{\max }}(P=.57) \\
\mathrm{P}_{\mathrm{E}_{\max }}(P=.64)\end{array}$ & \\
\hline
\end{tabular}


Table 2. (Continued)

\begin{tabular}{|c|c|c|c|c|}
\hline Reference & $\begin{array}{c}\text { PEDro }(n) \text {, Type of } \\
\text { Evidence, } \\
\text { Recommendation } \\
\text { Grade }\end{array}$ & Main Intervention & $\begin{array}{l}\text { Clinical Outcome } \\
\text { Measures }\end{array}$ & Self-Reported Outcome Measures \\
\hline Pinheiro et $\mathrm{al}^{21}$ & $\begin{array}{l}\text { PEDro: } 3 / 10(N=89) \text {, } \\
\text { cross-sectional study, } \\
\text { C }\end{array}$ & $\begin{array}{l}\text { Comparison of muscle strength in chronic } \\
\text { stroke subjects according to their gait } \\
\text { speed, subjects divided into community } \\
\text { (gait speed }>0.8 \mathrm{~m} / \mathrm{s} \text { ) and non- } \\
\text { community (gait speed }<0.8 \mathrm{~m} / \mathrm{s} \text { ) } \\
\text { ambulators }\end{array}$ & $\begin{array}{l}\mathrm{P}_{\mathrm{I}_{\max }}(P=.04) \\
\mathrm{P}_{\mathrm{E}_{\max }}(P=.25) \\
\mathrm{FEV}_{1}(P<.75) \\
\mathrm{FVC}(P<.75) \\
\mathrm{FEV}_{1} / \mathrm{FVC} \\
\quad(P<.75)\end{array}$ & N/A \\
\hline \multicolumn{5}{|c|}{$\begin{array}{l}\mathrm{RCT}=\text { randomized controlled trial } \\
\mathrm{P}_{\mathrm{I}_{\max }}=\text { maximum inspiratory pressure } \\
\mathrm{P}_{\mathrm{E}_{\max }}=\text { maximum expiratory pressure } \\
\mathrm{PEF}=\text { peak expiratory flow } \\
\dot{\mathrm{V}}_{\mathrm{O}_{2}}=\text { oxygen consumption } \\
6 \mathrm{MWT}=6 \text {-min walk test } \\
\mathrm{N} / \mathrm{A}=\text { none }\end{array}$} \\
\hline
\end{tabular}

A study ${ }^{19}$ compared respiratory muscle strength in chronic stroke subjects according to their physical activity levels and did not find statistically significant results regarding $\mathrm{P}_{\mathrm{I}_{\max }}$ and $\mathrm{P}_{\mathrm{E}_{\max }}$ outcome measures; however, a 6-min walk test showed statistically significant results regarding respiratory function in active subjects. Nevertheless, other cross-sectional research ${ }^{20}$ compared respiratory muscle strength in subjects after chronic and acute stroke and showed similar weaknesses in respiratory muscles in both phases. Thus, it was suggested that a program that includes respiratory muscle training for these individuals could improve rehabilitation after stroke.

Another study compared muscle strength in chronic stroke subjects according to their gait speed. It showed statistically significant differences between groups in $\mathrm{P}_{\mathrm{I}_{\max }}$, but statistically significant differences in $\mathrm{P}_{\mathrm{E}_{\max }}$ were not found. ${ }^{21}$ This study recommended respiratory muscle training, especially for subjects with lower functional levels.

\section{Evidence of Respiratory Muscle Training With a Threshold Valve in Subjects After Stroke}

Two primary documents gave an A recommendation grade to respiratory muscle training with a threshold valve in subjects after stroke; the authors showed functional and clinically important changes in most outcome measures in each study. ${ }^{8,9}$ One study had an evidence grade of C. ${ }^{5}$

First, in the study by Britto et al, ${ }^{8}$ subjects performed an 8 -week training inspiratory muscle protocol at least 5 $\mathrm{d} /$ week for $30 \mathrm{~min} / \mathrm{d}$, starting with an intensity of $30 \% \mathrm{P}_{\mathrm{I}_{\max }}$ and increased $2 \mathrm{~cm} \mathrm{H}_{2} \mathrm{O}$. At the end of the protocol, the force $\left(\mathrm{P}_{\mathrm{I}_{\max }}\right)$ and IME were significantly improved. Thus, the effect size increased to $34.4(P=.05)$, and IME increased by $17.4(P=.05)$. However, results from selfreport questionnaires (Brazilian quality-of-life question- naire according to the Nottingham Health Profile and the maximum physical activity questionnaire) did not show significant changes. The initial characteristics of participants and questionnaires employed were not sensitive to changes. Although if specific questionnaires had been used for patients with stroke symptoms, the results obtained would have been significant. ${ }^{8}$

On the other hand, stroke subjects who performed inspiratory muscle training found improvements in dyspnea, ${ }^{9}$ yet the group that carried out ventilatory re-education exercises improved only in peak expiratory flow. They carried out a program of conventional neurological rehabilitation that was supplemented by an inspiratory muscle training protocol with a threshold valve 6 times/week for 6 weeks with an initial load of $40 \%$ until they reached $60 \%$ of the $\mathrm{P}_{\mathrm{I}_{\max }}$. Training was performed for 2 sessions/d, with each session lasting $15 \mathrm{~min}$. After 6 weeks of the training intervention (which showed improvements in muscular inspiratory function associated with an increase in lung volume and exercise capacity), an improvement in dyspnea and quality of life was found using the 12-item Medical Outcomes Study Short Form questionnaire. However, the group that performed diaphragmatic and respiratory exercises with pursed lips and the control group did not show improvement.

Only Kulnik et $\mathrm{al}^{5}$ simultaneously incorporated a neurological PR program and expiratory muscle training. In the design of this research, there were 3 different groups: a control group, which performed a PR program simultaneously with respiratory muscle training at a constant load of 10\%; the second group, which carried out a PR program and expiratory muscle training with resistance at 50\%; and the final group, which carried out a PR program and inspiratory muscle training with resistance at $50 \%$. 


\section{Inspiratory Muscle Training in SubJects After Stroke}

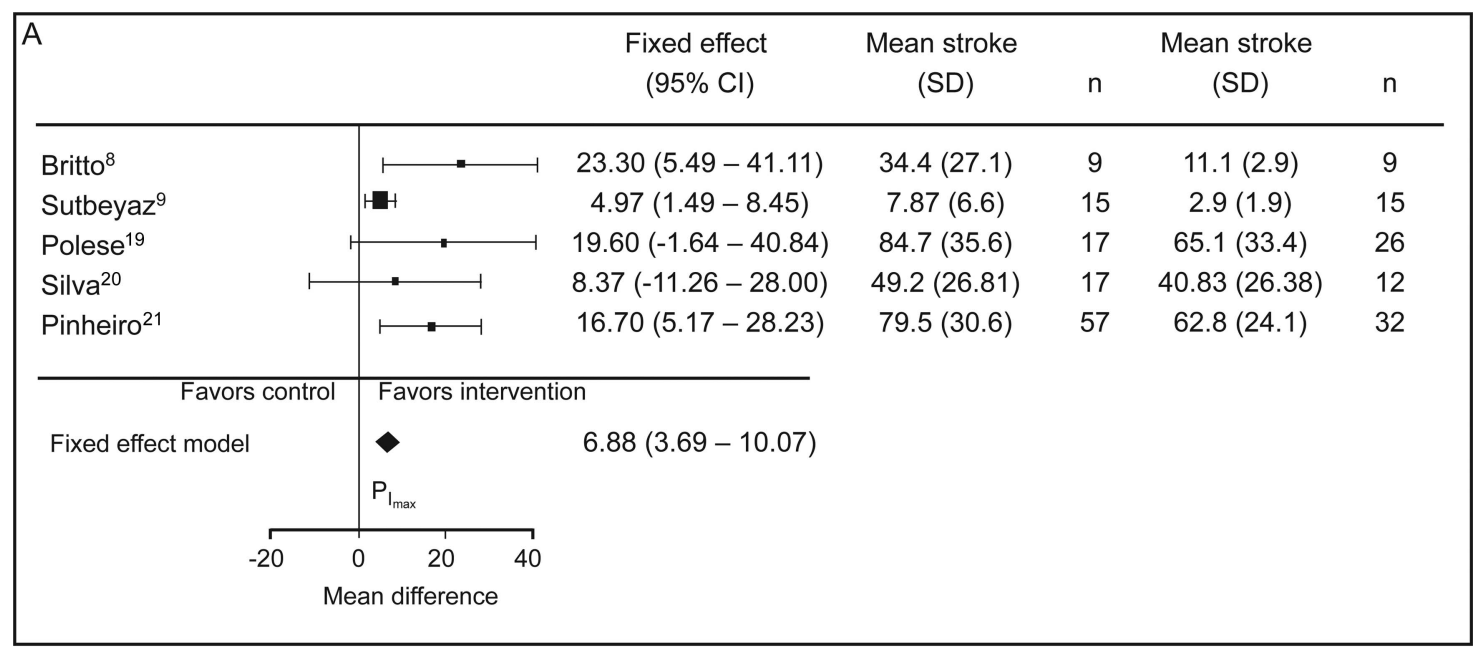

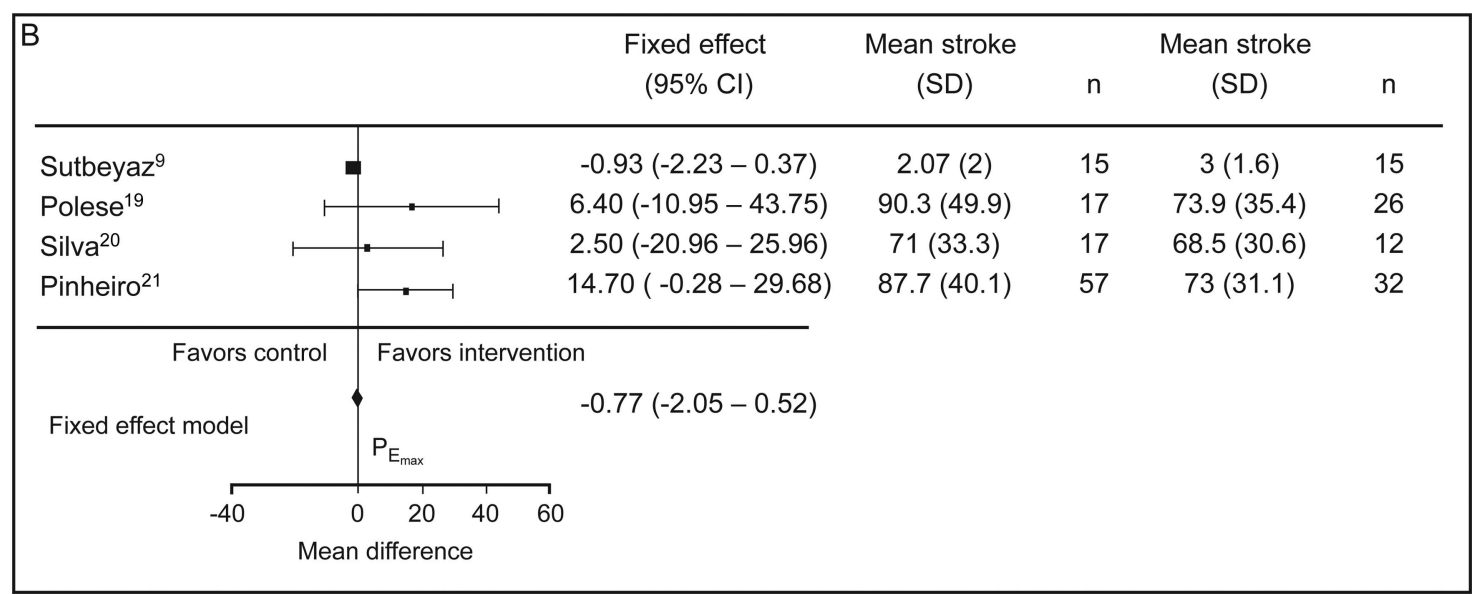

Fig. 1. Meta-analysis of data of selected studies on $P_{I_{\max }}(A)$ and $P_{E_{\max }}(B)$.
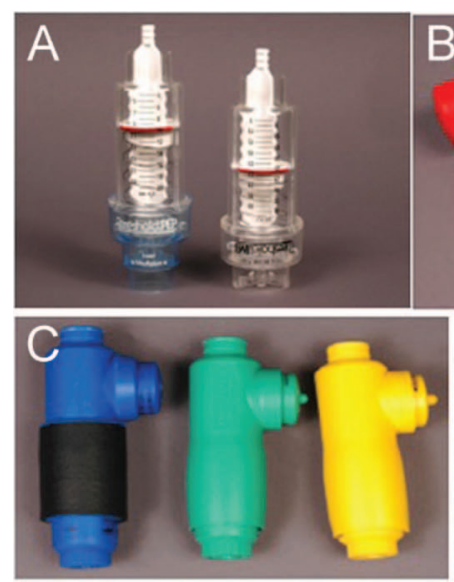
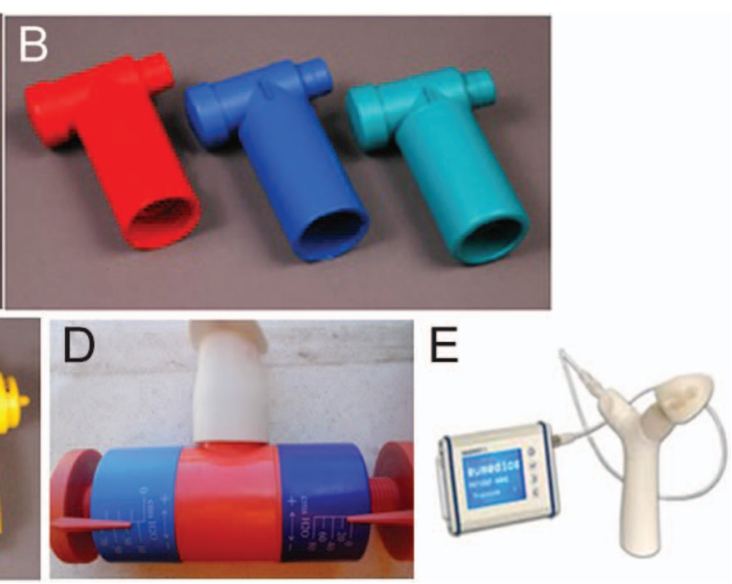

Fig. 2. Examples of thresholds valves in respiratory training. A: Threshold IMT. B: POWERbreathe. C: PowerLung. D: ORYGEN DUAL. E: Respifit S.

\section{Practical Implications of the Incentive Spirometer for Ventilatory Re-Education}

Incentive spirometers play a crucial role in preventing the reduction of mobility of the thoracic cage, and con- ventionally, spirometers carry out thoracic expansion..$^{22}$ There are 2 types of spirometers: volume and flow. ${ }^{12}$ The incentive volume spirometer provides an increase in thoracic expansion and reduces asymmetries of these expansions. ${ }^{12}$ Thus, spirometers are recommended for patients 
undergoing stroke rehabilitation. Moreover, the incentive flow spirometer requires more muscle activity in older people because it needs to move a larger volume of air into the thoracic cage. ${ }^{22}$ Therefore, it is necessary to make a preliminary assessment of patients to consider which kind of spirometer is better suited to their age and clinical conditions.

Subjects who performed breathing exercises with spirometers showed a significant increase in peak expiratory flow. ${ }^{9}$ In addition, in a recent study, improvements in peak expiratory flow were found for inspiratory muscle training with resisted loads. ${ }^{5}$

In this search, we highlighted 3 studies regarding ventilatory re-education through conventional breathing techniques. ${ }^{8}{ }^{10,11}$ In these studies, subjects completed exercises that improved breathing capacity. These exercises consisted of learning diaphragmatic breathing; for example, the physiotherapist told the subject to conduct an inspiration to fill the abdomen ${ }^{26}$ or to use inspiratory exercises combined with breathing through pursed lips. ${ }^{10}$ The physiotherapist helped in proprioception work by placing his or her hand on the subject's abdomen, which facilitated the understanding of abdominal breathing. The physiotherapist used a proprioceptive signal from the breathing equipment to tell subjects when to exhale slowly. ${ }^{10,11}$

\section{Threshold Devices to Train Respiratory Muscles}

There are 5 types of available devices with respiratory valves: Threshold IMT (Philips Respironics, Murrysville, Pennsylvania), POWERbreathe (HaB International, Southam, Warwickshire, United Kingdom), PowerLung (PowerLung, Houston, Texas), Respifit S (Biegler, Mauerbach, Austria), and ORYGEN DUAL (FORUMED, S.L., Catalonia, Spain) (Fig. 2). All articles in this systematic review used the Threshold IMT device, which uses $30 \%$ of the $\mathrm{P}_{\mathrm{I}_{\max }}$ to $41 \mathrm{~cm} \mathrm{H}_{2} \mathrm{O}$ (the maximum load that this device can reach). ${ }^{27}$ The great dearth of studies in this neurological field was a very limiting factor. In fact, only 6 studies on respiratory muscle training were found. Additional studies are required to advance and strengthen existing scientific evidence, which was both limited and varied in its findings. Larger sample sizes are needed to improve respiratory muscle training.

Finally, it is necessary to carry out a protocol of therapeutic respiratory muscle training interventions for 8 weeks, with a frequency of 3 or $6 \mathrm{~d} /$ week for one or two sessions. Each session should consist of $30 \mathrm{~min} / \mathrm{d}$ or $15 \mathrm{~min} / \mathrm{set}, 2$ sets/d, with an intensity of $30-40 \%$ of $\mathrm{P}_{\mathrm{I}_{\max }}$.

\section{Conclusion}

This research has examined levels of evidence and recommendation grades of various therapeutic interventions of inspiratory muscle training in people who have suffered a stroke. It has been observed that respiratory muscle training can improve strength and endurance of respiratory muscles in these subjects. At least one 8-week intervention carried out at a frequency of 3 to 6 days/week is recommended. Each session should last between 15 and 30 minutes per set with one or 2 daily sessions per day at an intensity of $30-40 \%$ of maximal inspiratory pressure. It is necessary to use the suitable spirometer for each person. The results of this research support physiotherapy respiratory techniques in people who have suffered a stroke.

\section{REFERENCES}

1. Hannawi Y, Hannawi B, Rao CP, Suarez JI, Bershad EM. Strokeassociated pneumonia: major advances and obstacles. Cerebrovasc Dis 2013;35(5):430-443.

2. Wilson RD. Mortality and cost of pneumonia after stroke for different risk groups. J Stroke Cerebrovasc Dis 2012;21(1):61-67.

3. Working group on prevention guide stroke. Iberoamerican Cochrane Center, coord. Clinical Practice Guideline: primary and secondary ictus prevention. CPG (AATRM No. 2006/15). Madrid: National Health Service quality strategy. Agency Technology Assesment and Health Research; 2008.

4. Xiao Y, Luo M, Wang J, Luo H. Inspiratory muscle training for the recovery of function after stroke. Cochrane Database Syst Rev 2012; 5:CD009360.

5. Kulnik ST, Rafferty GF, Birring SS, Moxham J, Kalra L. A pilot study of respiratory muscle training to improve cough effectiveness and reduce the incidence of pneumonia in acute stroke: study protocol for a randomized controlled trial. Trials 2014;15:123.

6. Teixeira-Salmela LF, Olney SJ, Nadeau S, Brouwer B. Muscle strengthening and physical conditioning to reduce impairment and disability in chronic stroke survivors. Arch Phys Med Rehabil 1999; 80(10):1211-1218.

7. Pollock RD, Rafferty GF, Moxham J, Kalra L. Respiratory muscle strength and training in stroke and neurology: a systematic review. Int J Stroke 2013;8(2):124-130.

8. Britto RR, Rezende NR, Marinho KC, Torres JL, Parreira VF, Teixeira-Salmela LF. Inspiratory muscular training in chronic stroke survivors: a randomized controlled trial. Arch Phys Med Rehabil 2011; 92(2):184-190.

9. Sutbeyaz ST, Koseoglu F, Inan L, Coskun O. Respiratory muscle training improves cardiopulmonary function and exercise tolerance in subjects with subacute stroke: a randomized controlled trial. Clin Rehabil 2010;24(3):240-250.

10. Kyo Chul S, Hyun Min L, Hyeon Ae K. The effects of combination of inspiratory diaphragm exercise and expiratory pursed-lip breathing exercise on pulmonary functions of stroke patients. J Phys Ther Sci 2013;25(3):241-244.

11. Lee J, Seo K, Kim K. Measurement of changes in chest mobility and pulmonary functions in relation to stroke patients' positions. J Phys Ther Sci 2012;24:253-256.

12. Lima IN, Fregonezi GA, Melo R, Cabral EE, Aliverti A, Campos TF, Ferreira GM. Acute effects of volume-oriented incentive spirometry on chest wall volumes in patients after stroke. Respir Care 2014; 59(7):1101-1107.

13. Moher D, Liberati A, Tetzlaff J, Altman DG, PRISMA Group. Preferred reporting items for systematic reviews and meta-analyses: the PRISMA statement. Int J Surg 2010;8(5):336-341.

14. Adams HP Jr, Davis PH, Leira EC, Chang KC, Bendixen BH, Clarke WR, et al. Baseline NIH Stroke Scale score strongly predicts out- 


\section{Inspiratory Muscle Training in SubJects After Stroke}

come after stroke: a report of the Trial of Org 10172 in Acute Stroke Treatment (TOAST). Neurology 1999;53(1):126-131.

15. Maher CG, Sherrington C, Herbert RD, Moseley AM, Elkins M. Reliability of the PEDro scale for rating quality of randomized controlled trials. Phys Ther 2003;83(8):713-721.

16. Moseley AM, Herbert RD, Sherrington C, Maher CG. Evidence for physiotherapy practice: a survey of the Physiotherapy Evidence Database (PEDro). Aust J Physiother 2002;48(1):43-49.

17. Foley NC, Teasell RW, Bhogal SK, Speechley MR. Stroke rehabilitation evidence-based review: methodology. Top Stroke Rehabil 2003;10(1):1-7.

18. Verhagen AP, de Vet HC, de Bie RA, Kessels AG, Boers M, Bouter LM, Knipschild PG. The Delphi list: a criteria list for quality assessment of randomized clinical trials for conducting systematic reviews developed by Delphi consensus. J Clin Epidemiol 1998;51(12):1235-1241.

19. Polese JC, Pinheiro MB, Faria CD, Britto RR, Parreira VF, TeixeiraSalmela LF. Strength of the respiratory and lower limb muscles and functional capacity in chronic stroke survivors with different physical activity levels. Braz J Phys Ther 2013;17(5):487-493.

20. Silva SM, Corrêa JCF, da Silva FC, Sampaio LM, Corréa FI. Comparison of respiratory muscle strength between elderly subjects after a stroke. Acta Fisiatr 2013;20(1):20-23.

21. Pinheiro MB, Polese JC, Faria CD, Machado GC, Parreira VF, Britto RR, Teixeira-Salmela LF. Inspiratory muscular weakness is most evident in chronic stroke survivors with lower walking speeds. Eur J Phys Rehabil Med 2014;50(3):301-307.

22. Lunardi AC, Porras DC, Barbosa RC, Paisani DM, Marques da Silva CC, Tanaka C, Carvalho CR. Effect of volume-oriented versus floworiented incentive spirometry on chest wall volumes, inspiratory muscle activity, and thoracoabdominal synchrony in the elderly. Respir Care 2014;59(3):420-426.

23. Chiara T, Martin D, Sapienza C. Expiratory muscle strength training: speech production outcomes in patients with multiple sclerosis. Neurorehabil Neural Repair 2007;21(3):239-249.

24. Martín-Valero R, Zamora-Pascual N, Armenta-Peinado JA. Training of respiratory muscles in patients with multiple sclerosis: a systematic review. Respir Care 2014;59(11):1764-1772.

25. Charususin N, Gosselink R, Decramer M, McConnell A, Saey D, Maltais F, et al. Inspiratory muscle training protocol for patients with chronic obstructive pulmonary disease (IMTCO study): a multicentre randomised controlled trial. BMJ Open 2013;3(8):e003101.

26. Billinger SA, Taylor JM, Quaney BM. Cardiopulmonary response to exercise testing in people with chronic stroke: a retrospective study. Stroke Res Treat 2012;2012:987637.

27. Silveira JM, Gastaldi AC, Boaventura Cde M, Souza HC. Inspiratory muscle training in quadriplegic patients. J Bras Pneumol 2010;36(3): 313-319. 